\title{
Effect of a Cultures of Aspergillus oryzae on Inflammatory Response and mRNA Expression in Intestinal Immune-Related Mediators of Male Broiler Chicks
}

\author{
Kazuaki Takahashi \\ Graduate School of Agricultural Science,Tohoku University, Sendai, 981-8555, Japan
}

\begin{abstract}
Effect of Aspergillus oryzae (CAO) culture on systemic inflammatory response and mRNA expression of immune-related mediators in intestine was studied in male broiler chicks. Feeding CAO alleviated enhancement of early inflammatory response such as changes in acute phase substance and growth performance during immunological stress induced by lipopolysaccharide and Sephadex. Furthermore, changes in mRNA expression of immune-related mediators in the upper and lower intestine at 5 and 14 days of age were investigated in chicks fed a diet with antibiotics, CAO or without both as control. The CAO and antibiotic feeding lowered interferon (IFN)- $\gamma$ and interleukin (IL)- $1 \beta$ mRNA expression compared to the control group. The expressions of toll like receptor (TLR)-4 mRNA in the antibiotic and CAO fed group were greater than that of the control group at 5 days of age, but not at 14 days of age. The findings suggest that CAO has anti-inflammatory effect and changes in IFN- $\gamma$, IL- $1 \beta$ and TLR-4 mRNA in immune-related cells of the gut in the CAO fed chicks appears to be similar to that of the antibiotics fed group. These immune-related mediators in the intestine may be a useful marker to select alternative to antibiotics.
\end{abstract}

Key words: Aspergillus oryzae culture, gut immunity, inflammatory response, mRNA expression

$$
\text { J. Poult. Sci., 49: 94-100, } 2012
$$

\section{Introduction}

A recent trend for broiler chickens to be selected for precocity and thereby an early marketing age highlights the importance of metabolism and nutrition during post-hatch period in chickens. Use of antibiotics to promote growth in poultry is banned in European Union and is limited in Japan. Control of immune system by certain nutrients or non antibiotic substances in broiler chickens appears to be a way to avoid or lower use of antibiotics because dietary immunomodulators that enhance humoral immunity and minimize immunological stress in chickens might improve the growth performance most positively (Klasing, 1998).

Formation of the microbiota starts shortly after birth and quickly expands into a complex and dynamic system that fulfils important roles in promoting health of the host. Principal functions include protecting invading pathogens and stimulating gut morphology as well as immune development and maintenances. Different commensal species of gut microorganisms not only exert their immune-stimulating effects

Received: August 1, 2011, Accepted: December 12, 2011

Released Online Advance Publication: January 25, 2012

Correspondence: K. Takahashi, Department of health and nutrition, Yamagata prefectural Yonezawa Women's Junior College, 6-15-1 Torimachi, Yonezawa, 992-0025, Japan. (E-mail :k-takahahi@yone.ac.jp) in different locations within the gut, but also the complexity by which the commensal microbiota modulates the host's immune system. Composition of the intestinal commensal microbiota has major effects on the host mucosal immune system. Cross-talk between the microbiota and the gut immune system is not only regulated as the immune system must be able to mount active responses against pathogens, but also maintains tolerance against harmless food and commensal bacterial antigens. Development and immunological function in the avian gut-associated lymphoid tissue (GALT) appears to be critical for chick survival immediately after hatch since GALT is exposed to adult type microflora from concomitant foraging and environment. Age-related changes in GALT of chickens have been reported which show that GALT contains functionally immature $\mathrm{T}$ and $\mathrm{B}$ lymphocytes at hatch, and that the function of these cells is attained during the first 2 weeks of life (Bar-Shira et al., 2003; Miyazaki et al., 2007). Sato et al. (2009) showed that administration of immunobiotic lactic acid bacteria enhanced immune competence in GALT of chicks during 3-7 days after hatching. We showed that an antibiotic feeding accelerates functional maturation of intestinal immune-related cells of male broiler chicks after hatch (Takahashi et al., 2011).

Understanding the mode of action of antibiotics and other growth permitting agents prospected for chickens such as 
immunobiotic lactic acid bacteria and on GALT function and/or maturation is a key for the development of an alternative way to avoid or decrease the use of antibiotics. It is thought that probiotics and prebiotics would be major candidate(s) of antibiotic alternatives. Culture of Aspergillus oryzae (CAO) and Aspergillus oryzae itself have been applied as a growth promoter in domestic animals (Lee et al., 2006). Recently, it was reported that CAO produced extracellular anti-microbial protein together with probiotics and prebiotics effects (Park et al., 2008). However, there is scarcity of available information about effect and mechanism of $\mathrm{CAO}$ to influence intestinal immune competences. Administration of antibacterial substances is known to reduce the inflammatory response. It has been shown that these nutrients are used much for production and growth than the immune response (Klasing, 1998). The changes in inflammatory response, therefore, appear to be an indicator for selecting alternatives to antimicrobial drugs. In the present experiment, we investigated if $\mathrm{CAO}$ feeding shows alleviating effect to immunological stimulation by injections of lipopolysaccharide (LPS) and Sephadex. After confirming the growth permission action of $\mathrm{CAO}$, we determined effect of CAO on mRNA expression of immune-related mediators; interferon (IFN)- $\gamma$, interleukin (IL)- $1 \beta$, IL-10, transforming growth factors (TGF)-b, toll-like receptor (TLR)-2, TLR-4, IL-2, CD3 and Bu-1 in the gut of broiler chicks during 14 days of age.

\section{Materials and Methods}

\section{Animals, Diets and Tissue Sampling}

In first experiment, newly hatched male broiler chicks (Ross strain) were obtained from a local commercial hatchery. Chicks were kept in electrically heated cages at $34^{\circ} \mathrm{C}$. The temperature was gradually lowered to $24^{\circ} \mathrm{C}$ at 14 days of age and birds were provided a corn-soybean meal based diet (maize $534.5 \mathrm{~g}$, soybean meal $373.5 \mathrm{~g}$, soybean oil $50 \mathrm{~g}$, calcium phosphate $17.5 \mathrm{~g}$, calcium carbonate $10.3 \mathrm{~g}$, sodium chloride $3.3 \mathrm{~g}$, DL-methionine $2.5 \mathrm{~g}$, L-lysine $0.4 \mathrm{~g}$, and mineral and vitamin mixture $4 \mathrm{~g}$ per $\mathrm{kg}$ diet) without antibiotics as a basal diet. Calculated metabolizable energy and crude protein content in the diet were $13.1 \mathrm{MJ}$ and $220 \mathrm{~g}$ per kg diet, respectively. CAO used in this experiment were made of unpolished rice and Aspergillus oryzae. It contains enriched digestible enzymes such as acidic amylase, protease, and also contains peptides and polysaccharide components. At 7 days of age, male birds were allocated to 2 groups of 20 chicks each and provided the corn-soybean meal based diet with or without $1 \% \mathrm{CAO}$ to 21 days of age. Two chicks were placed in each cage from 10 days of age. Last 6 days of experimental diets feeding, half of the chicks per replicate fed the same diets were intraperitoneally injected with Escherichia coli LPS at $500 \mathrm{mg} / \mathrm{kg}$ BW on days 1,3 and 5 and with Sephadex-G50 at $500 \mathrm{mg} / \mathrm{kg} \mathrm{BW}$ on days 2 and 4 . LPS was dissolved in a sterilized saline $(0.9 \% \mathrm{NaCl}$ solution $)$ at a concentration of $500 \mathrm{mg} / \mathrm{ml}$. Sephadex G-50 superfine was dissolved at $5 \mathrm{~g}$ in $100 \mathrm{~m} l$ in the sterilized saline. Diet and water were provided freely. The control group was injected with sterilized saline alone in the same manner as in the LPS and Sephadex injected groups. Blood sample was taken at 9 and $24 \mathrm{~h}$ after the first LPS injection.

In second experiment, newly hatched Ross broiler strain (male) was obtained from a local commercial hatchery. Birds were allocated to 3 groups with 15 chicks in each group. Chicks were provided the corn-soybean meal based diet (as a control diet), the control diet containing antibiotics with or without (sodium Salinomycin and Enramycin hydrochloride), or the control diet with CAO (1\% of diet). Antibiotics were incorporated into the diet as per recommended concentrations by the Japanese Feeding Standard. Diet and water were provided ad libitum. At five and 14 days of age, 6 chicks in each dietary group were sacrificed by decapitation. Gut was removed and flushed with a cold phosphate buffer containing $154 \mathrm{mM} \mathrm{NaCl}, 3 \mathrm{mM} \mathrm{KCl}, 12 \mathrm{mM} \mathrm{Na}_{2}$ $\mathrm{HPO}_{4}$, and $2 \mathrm{mM} \mathrm{KH}_{2} \mathrm{PO}_{4}\left(\mathrm{pH} 7.4,0^{\circ} \mathrm{C}\right)$. Cross-sections of the upper gut (about $1 \mathrm{~g}$, from the end of duodenum to middle section of jejunum), and the lower gut (from the end of ileum to the upper section of colon excluding caecum) were collected and frozen in liquid nitrogen. Two sections of the gut were stored at $-80^{\circ} \mathrm{C}$ until analysis. The Animal Care and Use Committee of the Graduate School of Agriculture of Tohoku University approved all procedures.

\section{Determination of Plasma a1-acid Glycoprotein (AGP), Ceruloplasmin Nitrite Concentration}

The method of determination of plasma a1-acid glycoprotein (AGP), ceruloplasmin, nitrite and nitrate (NOx) concentration was described in our previous report (Takahashi et al., 2009).

\section{Quantitation of mRNA using Real-time PCR}

Total RNA was extracted from chick gut using Trizol reagent (Invitrogen). To study the expression of particular chick immune genes, real-time reverse transcription-polymerase chain reaction (RT-PCR) analysis was performed using the iCycler Real Time Detection System (Bio-Rad Laboratories). The reverse transcription, amplification, detection methods and primer sequences used were same as previously described (Miyazaki et al., 2007). At the end of each run, melting curve profiles were recorded. Analysis of the standard curve from each product allowed calculation of the mRNA levels of the respective genes. Results are presented as the ratio of each gene to GAPDH, to correct for differences in the amounts of template DNA used.

\section{Statistical Analysis}

A two (dietary treatments) by two (immune stimulatory conditions) factorial range test was applied to analyze the data in experiment 1 by using SAS (SAS Institute, USA). Data within the same sampling day and intestinal region was subjected to one-way analysis of variance of SAS in experiment 2. Mean values were compared using Tukey's multiple range test. Statistical significance was interpreted as values of $P<0.05$.

\section{Results}

Table 1 shows results of experiment 1 . The treatment of LPS and Sephadex injection lowered body weight gain and 
Table 1. Effect of culture of Aspergillus oryzae supplementation on growth performance over LPS and sephadex injection periods for 6 days and on changes in plasma concentration of alpha-1 acid glycoprotein (AGP), ceruloplasmin (Cer) at 24 $\mathrm{h}$ and nitrate plus nitrite (NO) at $9 \mathrm{~h}$ following the first LPS injection

\begin{tabular}{|c|c|c|c|c|c|c|c|c|}
\hline \multirow{2}{*}{$\begin{array}{l}\text { Stress }^{1} \\
\mathrm{CAO}\end{array}$} & & \multicolumn{2}{|c|}{ No } & \multicolumn{2}{|c|}{ Yes } & \multicolumn{3}{|c|}{ Probability } \\
\hline & & Control & CAO & Control & $\mathrm{CAO}$ & Stress & $\mathrm{CAO}$ & Interactions \\
\hline Feed intake ${ }^{2}$ & $\mathrm{~g}$ & $361 \pm 17$ & $372 \pm 14$ & $336 \pm 18$ & $332 \pm 13$ & NS & NS & NS \\
\hline $\mathrm{BW}$ gain $^{2}$ & $\mathrm{~g}$ & $227 \pm 11$ & $243 \pm 5$ & $200 \pm 6$ & $216 \pm 9$ & $<0.01$ & $<0.01$ & NS \\
\hline Feed efficiency ${ }^{2}$ & $\mathrm{~g} / \mathrm{g}$ & $0.635 \pm 0.035$ & $0.652 \pm 0.020$ & $0.592 \pm 0.020$ & $0.651 \pm 0.011$ & $<0.01$ & $<0.01$ & $<0.01$ \\
\hline Plasma & & & & & & & & \\
\hline $\mathrm{NOx}^{3}$ & $\mathrm{nmol} / \mathrm{m} l$ & $27.1 \pm 1.4$ & $18.3 \pm 1.7$ & $121.8 \pm 38.9$ & $86.9 \pm 27.8$ & $<0.05$ & $<0.01$ & $<0.01$ \\
\hline Ceruloplasmin $^{3}$ & $\mathrm{mg} / \mathrm{l}$ & $11.2 \pm 5.0$ & $12.4 \pm 3.5$ & $39.9 \pm 12.2$ & $20.4 \pm 5.8$ & $<0.05$ & $<0.01$ & $<0.01$ \\
\hline $\mathrm{AGP}^{3}$ & $\mathrm{mg} / \mathrm{l}$ & $171 \pm 55$ & $208 \pm 84$ & $755 \pm 110$ & $589 \pm 77$ & $<0.05$ & $<0.01$ & $<0.01$ \\
\hline
\end{tabular}

${ }^{1}$ Intraperitoneal injection with Escherichia coli LPS at $500 \mathrm{mg} / \mathrm{kg}$ BW on days 1, 3 and 5 and with Sephadex-G50 at $500 \mathrm{mg} / \mathrm{kg}$ BW on days 2 and 4 .

${ }^{2}$ Mean \pm SE (5 observations) on a cage basis

${ }^{3}$ Mean \pm SE (10 observations)
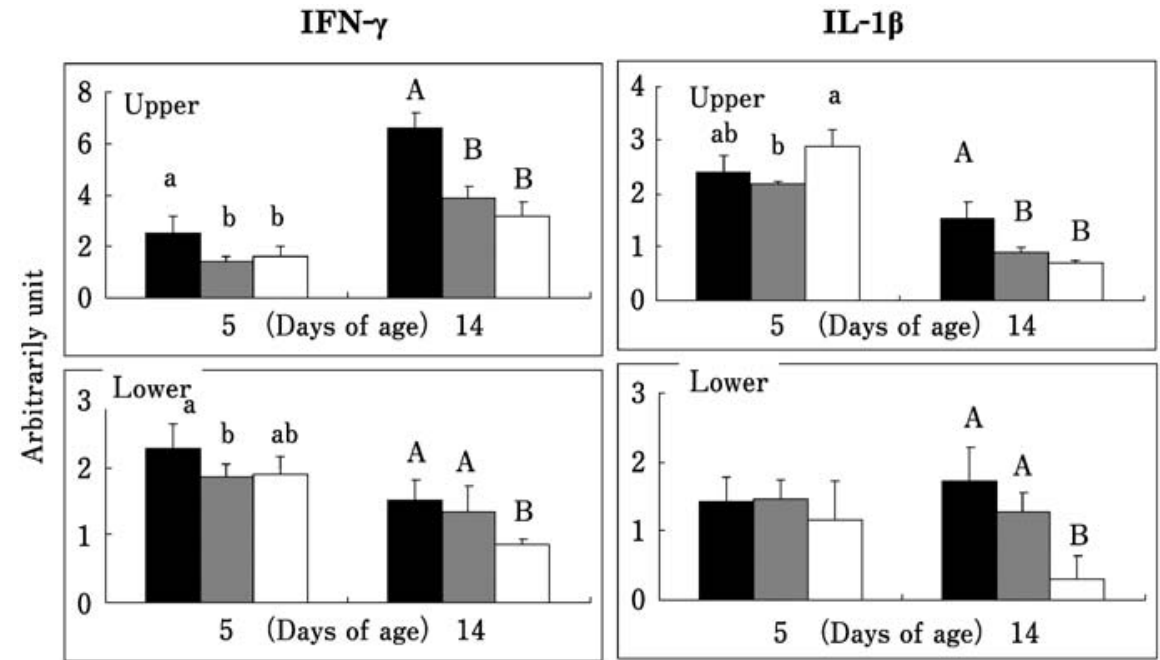

Control $\square$ Antibiotics $\square$ Cultures of A.Orzyae

Fig. 1. Expression of interferon (IFN)- $\gamma$ and interleukin (IL)-1 $\beta$ mRNA in the upper and lower intestine of chicks fed diet with or without a culture of Aspergillus oryzae at 5 and 14 days of age. Each bar represents the mean and standard deviation from 6 individual chickens. a, b, c or A, B, C: $P<0.05$.

feed efficiency $(P<0.05)$. The CAO fed group showed higher body weight gain and feed efficiency over the periods of the LPS and Sephadex injection compared to the control group $(P<0.01)$. It has been known that ceruloplasmin, AGP and NOx were acute phase reactants in avian. Our previous study showed that the generation of acute phase reactants is known to be caused by increased production of proinflammatory cytokines. An increase in plasma ceruloplasmin, AGP and NOx concentrations was highest at 24 and $9 \mathrm{~h}$ following intraperitoneal LPS injection, respectively (Takahashi et al.,. 1997, 2000 and 2009) The first LPS injection increased plasma AGP and ceruloplasmin concentration at $24 \mathrm{~h}$ and NOx concentration at $9 \mathrm{~h}$ following the injection $(P<0.05)$. The CAO fed group showed the prevention of those enhancements $(P<0.01)$.

Expression of IFN- $\gamma$ and IL- $1 \beta$ mRNA as maker of proinflammatory mediators in the intestine is shown in Fig 1. IFN- $\gamma$ mRNA expressions in the antibiotics and CAO fed groups were significantly lower than those in the control group at 5 and 14 days after hatch in the upper intestines $(P$ $<0.05)$. In the lower intestine, changes in the expression were similar in the upper intestine among the dietary treatment groups but the expression in the antibiotics fed group was not significantly different from that in the control group at 14 days of age. IL- $1 \beta$ mRNA expression in the antibiotics and CAO fed groups were significantly lower than those in 
IL-10
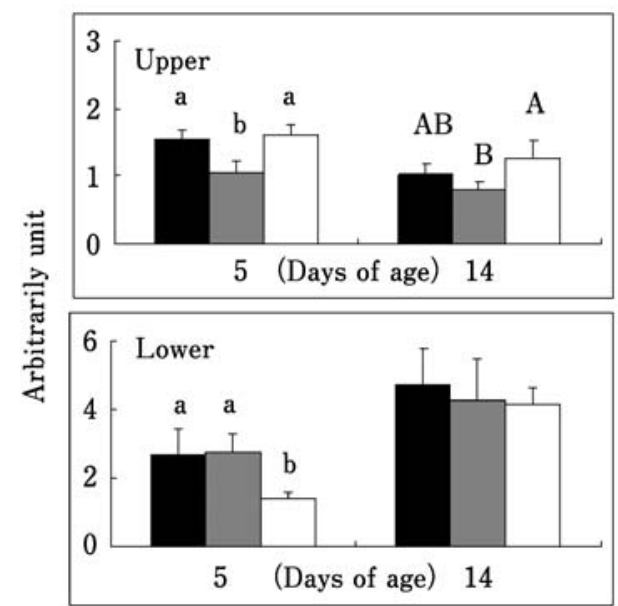

TGF- $\beta$
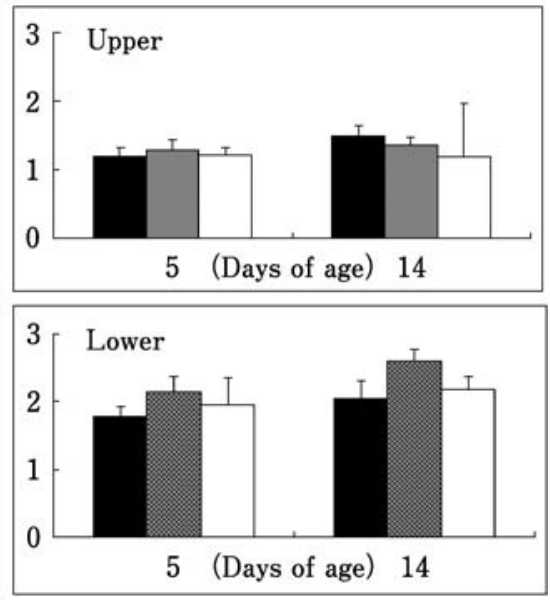

Control $\square$ Antibiotics $\square$ Cultures of A.Orzyae

Fig. 2. Expression of interleukin (IL) -10 and transforming growth factor (TGF)- $\beta$ mRNA in the upper and lower intestine of chicks fed diet with or without a culture of Aspergillus oryzae at 5 and 14 days of age. Each bar represents the mean and standard deviation from 6 individual chickens. a, b, c or A, B, C: $P<0.05$.

TLR-4
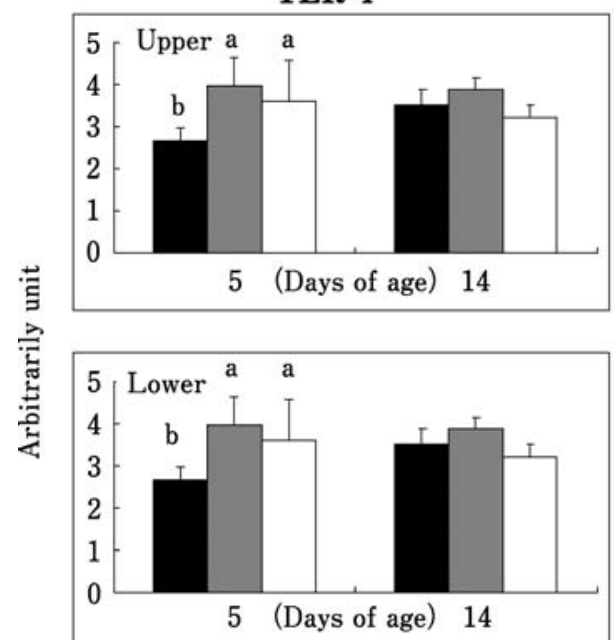

\section{TLR-2}
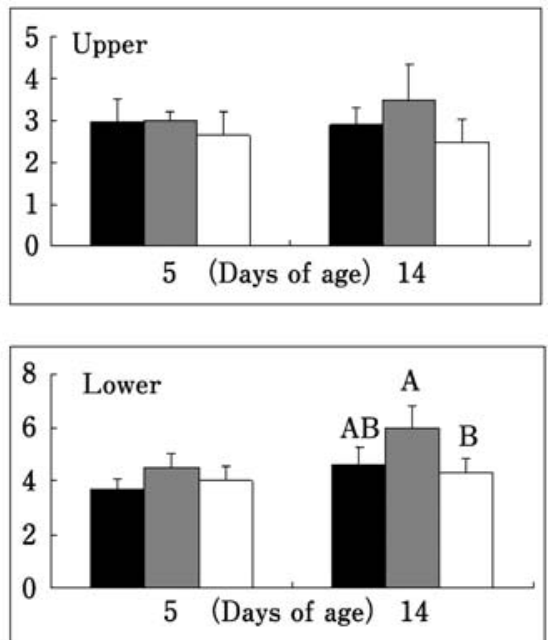

Control $\square$ Antibiotics

Cultures of A.Orzyae

Fig. 3. Expression of Toll-like recieptor (TLR)-2 and -4 mRNA in the upper and lower intestine of chicks fed diet with or without a of Aspergillus oryzae at 5 and $\mathbf{1 4}$ days of age. Each bar represents the mean and standard deviation from 6 individual chickens. a, b, c or A, B, C: $P<0.05$.

the control group at 14 days after hatch in the lower and upper intestine $(P<0.05)$, but at 5 days of age, the expression in the CAO fed group was higher than that in the antibiotics fed group $(P<0.05)$. The IL- $1 \beta$ expression did not differ among the treatments in the lower intestine at 5 days of ages.
Expression of IL-10 and TGF-b mRNA in the intestine is shown in Fig 2 as maker of anti-inflammatory or T cell regulatory mediators. The antibiotics fed group showed lower IL-10 mRNA expression at 5 and 14 days of age in the upper intestine $(P<0.05)$. The CAO fed group at 5 days of age had 
CD3

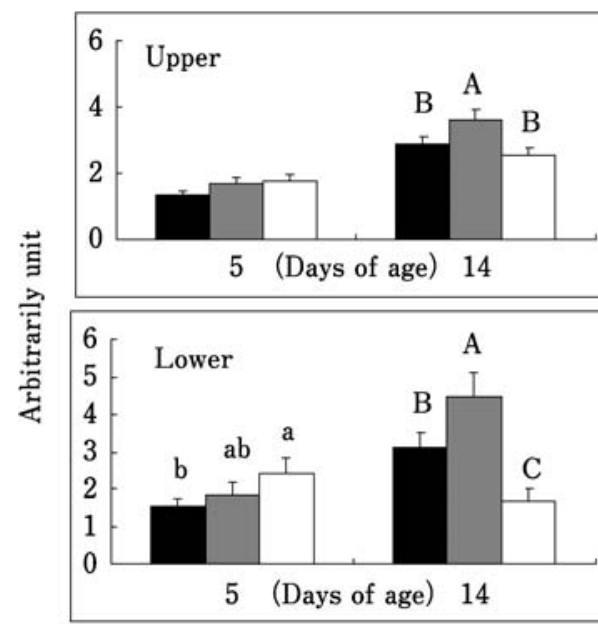

Bu-1

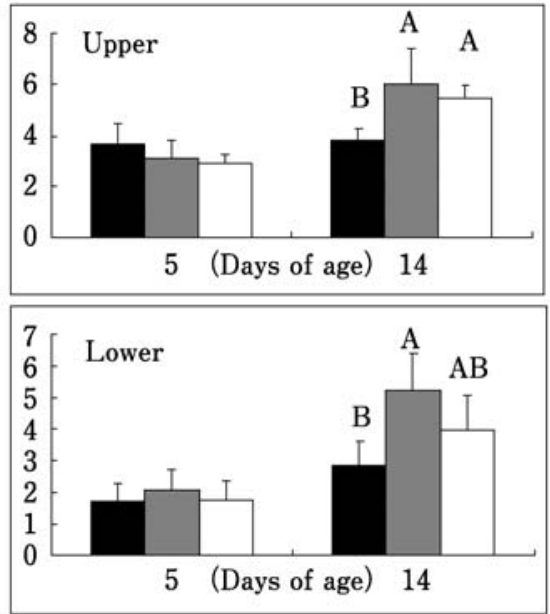

Control $\square$ Antibiotics $\square$ Cultures of A.Orzyae

Fig. 4. Expression of CD3 and Bu-1, mRNA expression $i$ in the upper and lower intestine of chicks fed diet with or without a culture of Aspergillus oryzae at 5 and 14 days of age. Each bar represents the mean and standard deviation from 6 individual chickens. $\mathrm{a}, \mathrm{b}, \mathrm{c}$ or $\mathrm{A}, \mathrm{B}, \mathrm{C}: P<0.05$.

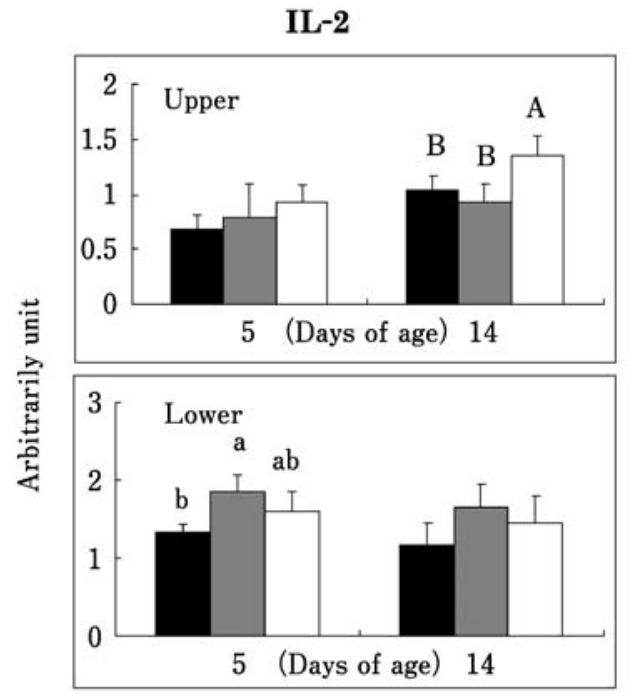

Control $\square$ Antibiotics $\square$ Cultures of A.Orzyae

Fig. 5. Expression of interleukin (IL)-2 mRNA expression in the upper and lower intestine of chicks fed diet with or without a culture of Aspergillus oryzae at 5 and 14 days of age. Each bar represents the mean and standard deviation from 6 individual chickens. a, b, c or A, B, C: $P$ $<0.05$.

lower the expression compared to the other groups in the lower intestine $(P<0.05)$. TGF-b mRNA expression among the treatments did not differ regardless of the sampling age and the intestinal section.
Fig. 3 shows expression of TLR-2 and 4 mRNA in the intestine as a maker or pathogen pattern recognized receptors. Expression of TLR-4 mRNA in the antibiotics and CAO fed groups was greater than that in the control group at 5 days of age in the upper and lower intestine $(P<0.05)$, but did not differ among the treatments at 14 days of age in both intestinal sections. The antibiotics fed group showed greater TLR-2 mRNA expression in the lower intestine compared to that in the other groups at 14 days of age $(P<0.05)$, but did not differ among the treatments in the upper section of intestine.

Fig. 4 shows expression of $\mathrm{CD} 3$ and $\mathrm{Bu}-1$ mRNA in the intestine as a marker of $\mathrm{T}$ cell and $\mathrm{B}$ cell numbers. The antibiotics fed group showed greater CD3 mRNA expression in the lower and upper intestine compared to that in the other groups at 14 days of age $(P<0.05)$. The CAO fed group had the lowest expression of CD3 in the lower section of intestine at 14 days $(P<0.05)$, but the higher expression in the $\mathrm{CAO}$ fed group was observed at 5 days of age $(P<0.05)$. Bu-1 mRNA expression in the control group was lower than that in the other groups at 14 days of age in the both sections of the intestine $(P<0.05)$. At 5 days of age, Bu-1 expression did not differ among the treatments in the upper and lower sections of the intestine.

Fig. 5 shows IL-2 mRNA expression in the intestine as a marker of $\mathrm{T}$ cell proliferation mediator. IL-2 mRNA expression at 14 days of age in the CAO fed group was greater than that in the other groups $(P<0.05)$. But at 5 days of age, the expression did not differ among the treatment regardless of section of the intestine. 


\section{Discussion}

Antimicrobial growth promoters like antibiotics, and probiotics in feed show anti-inflammatory and growth promoting effect under the dirty environmental condition in broiler chicks (Roura et al, 1992; Takahashi et al., 1997). Repeated injection of LPS and sephadex is a way to mimic dirty environment and immunological stimulation which was achieved by raising multiple cycle of chicks in the batteries, cages and rooms, by poor ventilation and by letting droppings, dust and dander accumulation in previous experiments (Takahashi et al., 2000). The results of the experiment 1 suggested that nature of CAO in terms of inflammatory response and growth performance is similar to antibiotics and probiotics in broilers reared dirty environmental conditions. Control of immune system by certain nutrients or non antibiotic substances appears to be an alternative way to use antibiotics because dietary immunomodulators that enhance humoral immunity and minimize immunological stress in chickens might improve the growth performance most positively (Klasing, 1998). Thus, CAO in feed is probably an efficient non-antibiotic growth promoter for chicks.

Suggested mechanisms of action for antibiotics are as follows: eradication of bacterial antigenic triggers, elimination of bacterial overgrowth, reduction of pro-inflammatory bacterial toxins, and potential immunosuppressive properties of antibiotics. These would lead to permit growth promotion and to increase feed utilization of animals under conventional breeding condition. The changes in microflora in response to antibiotics were considered a consequence of a direct effect of antibiotics on the microflora. However, the host itself has a large influence on the composition of the microbiota as a complex and dynamic ecosystem (Reid et al., 2003; Winkler et al., 2007). The different microbial compositions when using antibiotics as antimicrobial growth promoter are a consequence of an altered immune status rather than of a direct effect on the microbiota. Therefore, we hypothesized that use of dietary antibiotics down-regulate the mRNA expression of mediators related to immune competence in intestinal tract. Immune response in the upper intestine is not necessarily equal to that of the lower intestine (Miyazaki et al., 2007). It is generally considered that due to the variation in microbial flora of each site, the difference between flora are thought to be due to changes in oxygen concentration in the upper and lower small intestine. Therefore, mRNA expression of immune-related mediators and substances were determined in the upper and lower sites of chick's intestine. The results of the present experiment suggested that proinflammatory response related-cytokines such as IFN- $\gamma$ and pathogen pattern recognized receptors like TLR-4 (first stage of development or maturation of gut immune system) at early ages after hatch may be candidate marker to carry out an alternative analysis for antibiotics in feed of broiler chicks. The results also indicated that IL- $1 \beta$ and IFN- $\gamma$ at 14 days of age which is the final stage of development or maturation of gut immune system may be useful to analyze from the view point of immune related response. The pre- vious study indicated that the expression of most of the immune-related makers did not differ in the antibiotic fed and non-antibiotic fed groups, but some of the makers (IFN$\gamma, \mathrm{Bu}-1$ and TLR-4) in the non antibiotic fed group were greater at 15 days of age than those in the antibiotics fed group. Our results partly supported the hypothesis that the search for alternatives could be aimed to replace by nonantibiotic compounds with an effect on the inflammatory system similar to that of antimicrobial growth promoters mentioned by Niewold (2007). From those results, we proposed a method to select an alternative substance (s) to antibiotics would be as follows: (1) feeding periods of particular substances should be 5-7 or 14 days after hatch and (2) expression of IFN- $\gamma$, Bu- 1 and TLR- 4 mRNA in chick intestine are useful markers for the selection.

Anti-inflammation and modulation of gut-immune response of CAO would be due to the following mode of action (s) alone or in combinations; $\mathrm{CAO}$ has rich digestible enzyme activity, polysaccharides of Aspergillus oryzae that have prebiotic nature, and Aspergillus oryzae itself that is itself probiotic. It is estimated that antibiotics feeding enhance nutrients utilization caused by prevention of microorganism in intestine, and CAO dose increase beneficial microorganisms by increasing supply of exogenous digestible enzymes, since feeding a high starch diet was efficient to prevent inflammatory responses (Benson et al., 1993) and enhanced gut immune response (Miyazaki et al., 2007).

It has been rising number of knowledge how probiotc and prebiotic in feed affect gut and systemic immune competence with changes in gut microbial system (Brisbin et al., 2008; Gionchetti et al., 2006; Janardhana et al., 2009; Kabir, 2009; Lee et al., 2010a and b; Reid et al., 2003; Preidis and Versalovic, 2009; Winkler et al., 2007) although the exact mechanisms that exist in the chicken to control host responses through those non-antibiotics growth promoters are not completely clarified. Probiotics especially lactobacilli could modulate the systemic antibody response to antigens in chicks, and it effect on gut immune response were well studied (Higgins et al., 2008). Higher ratio of CD3 positive cell and changes in IFN- $\gamma$ mRNA expression in intestinal epithelial lymphocytes of broiler chicks was common phenomenon (Kabir, 2000; Lee et al., 2010a and b). According to the study of Lee et al. (2010a and b) the effect of various strains of Bacillus subtillus on gut immune status, higher ratio of CD3 positive cell and lower IFN $-\gamma$ mRNA expression in intestinal epithelial lymphocytes of broiler chicks was also observed. The responses of mRNA expression in immune related-mediators of gut in the antibiotic fed and CAO fed chicks were almost similar with each other as found in the present experiment. But CD3 mRNA expression in the CAO fed group was different from that in the antibiotics fed group. The result indicates that mode of action of CAO in regard to changes in immune-related mediators in gut is possibly different from that of the antibiotics used in this experiment and other non-antibiotics growth promoters.

It is thought that effect of feeding CAO on mRNA ex- 
pression of intestinal immune mediators attributes a nature of probiotics, polysaccharides, abundant digestible enzymes or their combination of $\mathrm{CAO}$ as mentioned above. However, from the changes in the profiles of immune-related mediators studied in this experiment, it is difficult to conclude concretely that which factor is a major to affect the immune system. For example, effects of feeding probiotic species with different strain on intestinal immune response are not same with each other (Kabir, 2000; Lee et al., 2010a and b). However, controlling of IFN- $\gamma$ production is one of the key factors to control gut-immune competence as obvious from the results of the present and that of early studies. Park et al. (2008) reported that CAO produced extracellular antimicrobial protein which might serve as controlling pathogenic microbial in the gut. Based on these results, further studies are needed to determine how feed supplementation of $\mathrm{CAO}$ can augment protective immunity against enteric pathogens in chickens and, which constituent(s) is induced by alterations in particular intestinal lymphocyte subpopulations or cytokine expression profiles, or by both components.

In conclusion, $\mathrm{CAO}$ feeding has anti-inflammatory action and changes in IFN- $\gamma$, IL- $1 \beta$ TLR- 4 mRNA in immune related cells of the gut in CAO fed chicks appears to be similar to those of the antibiotics fed group. These immunerelated substances in gut may be a useful marker to develop alternatives to antibiotics.

\section{Acknowledgments}

This works was supported in part by a Grant-in-Aid for Scientific Research C (No. 21580332) from the Japan Society for the Promotion of Science and IDEMITSU KOSAN CO., LTD. A culture of Aspergillus oryzae (IDEZAIMU) used in this study was provided by IDEMITSU KOSAN CO., LTD. The author is grateful to the assistance of Dr. Ahmad Mujahid in English editing.

\section{References}

Bar-Shira E, Sklan D and Friedman A. Establishment of immune competence in the avian GALT during the immediate posthatch period. Developmental and Comparative Immunology, 27: 147-157. 2003.

Benson BN, Calvert CC, Roura E and Klasing KC. Dietary energy source and density modulate the expression of immunologic stress in chicks. Journal of Nutrition, 123: 1714-1723. 1993.

Brisbin JT, Gong J and Sharif S. Interactions between commensal bacteria and the gut-associated immune system of chicks. Animal Health Research Reviews, 9: 101-110. 2008.

Gionchetti P, Rizzello F, Lammers KM, Morselli C, Sollazzi L, Davies S, Tambasco R, Calabrese C and Campieri M. Antibiotics and probiotics in treatment of inflammatory bowel disease. World Journal of Gastroenterology, 12: 3306-3313. 2006.

Higgins SE, Higgins JP, Wolfenden AD, Henderson SN, TorresRodriguez A, Tellez G and Hargis B. Evalution of a Lactobacillus-based probiotic culture for the reduction of salmonella enteritis in neonatal broiler chicks. Poultry Science, 87: 27-31. 2008 .

Janardhana V, Broadway MM, Bruce MP, Lowenthal JW, Geier MS, Hughes RJ and Bean GD. Prebiotics modulate immune responses in the gut-associated lymphoid tissue of chickens.
Journal of Nutrition, 139: 1404-1409. 2009.

Kabir SML. The reole of probiotics in the poultry industry. International Journal of Molecular Science, 10: 3531-3546. 2009.

Klasing KC. Nutritional modulation of resistance to infectious diseases. Poultry Science, 77: 1195-1125. 1998.

Lee KW, Lee SK and Lee BD. Aspergillus oryzae as probiotic in poultry -a review-. International Journal of Poultry Science, 5: 1-3 2006.

Lee KW, Lee SH, Lillehoj HS, Li GX, Jang SI, Babu US, Park MS, Kim DK, Lillehoj EP, Neumann AP, Rehberger TG and Siragusa GR. Effects of direct-fed microbials on growth performance, gut morphometry, and immune characteristics in broiler chickens. Poultry Science 89: 203-216. 2010a.

Lee KW, Lee SH, Lillehoj HS and Siragusa GR. Direct-fed microbials and their impact on the intestinal microflora and immune system of chickens. Journal of Poultry Science, 47: 106-114. 2010b.

Miyazaki Y, Takahashi K and Akiba Y. Developmental changes in mRNA expression in immune-associated cells of intestinal tract of broiler chickens after hatch and by dietary modification. Animal Science Journal, 78: 527-534. 2007.

Niewold TA. The nonantibiotic anti-inflammatory effect of antimicrobial growth promoters, the real mode of action? A hypothesis. Poultry Science, 86: 605-609. 2007.

Park SC, Yoo NC, Kim JY Park HK, Chae BJ, Shin SY, Cheong HS and Park YK. Isolation and characterization of an extracellular antimicrobial protein from Aspergillus orzyae. Journal of Agricultural and Food Chemistry, 56: 9647-9652. 2008.

Preidis GA and Versalovic J. Targeting the human Microbiome with antibiotics, probiotics, and prebiotics: gastroenterology enters the metagenomics era. Gastroenterology, 136: 2015-2031. 2009.

Reid G, Sanders ME, Gaskins HR, Gibson GR, Mercenier A, Rastall R, Roberfroid M, Rowland I, Cherbut C and Klaenhammer TR. New scientific paradigms for probiotics and prebiotics. Journal of Clinical Gastroenterology, 7: 105-118. 2003.

Roura E, Homedes J and Klasing KC. Prevention of immunologic stress contributes to the growth-permitting ability of dietary antibiotics in chicks. Journal of Nutrition, 122: 2383-2390. 1992.

Sato K, Takahashi K, Tohno M, Miura Y, Kamada T, Ikegami S and Kitazawa H. Immunomodulation in gut-associated lymphoid tissue of neonatal chicks by immunobiotic diets. Poultry Science, 88: 2532-2538. 2009.

Takahashi K, Akiba Y and Matsuda A. Effect of a probiotic on immune responses in broiler chicks under different sanitary conditions or immune activation. Animal Science and Technology (Japan), 68: 537-544. 1997.

Takahashi K, Akiba Y and Tamura K. Effect of repeated Sephadex Injection with or without Escherichia coli lipopolysaccharide on growth, immunocompetent organ weight and plasma alpha 1 acid glycoprotein concentration in broiler chicks reared in different stocking density. Animal Science Journal, 71: 268273. 2000.

Takahashi K, Miura Y and Mizuno T. Antibiotics feeding accelerate functional maturation of intestinal immune-related cells of male broiler chicks after hatch. Journal of Poultry Science, 48: 187-193. 2011.

Takahashi K, Takagi K and Akiba Y. Effect of dietary glycine supplementation and fish meal on inflammatory response in broiler chicks. British Poultry Science, 50: 479-486. 2009.

Winkler P, Ghadimi D, Schresenmeir J and Kraehenbuhl J-P. Molecular and cellular basis of microflora-host interactions. Journal of Nutrition, 137: 772S-772S. 2007. 